\title{
'Qualified'? A framework for comparing ELT teacher preparation courses
}

\author{
Phiona Stanley, UNSW Australia phiona.stanley@unsw.edu.au \\ Neil Murray, University of Warwick N.L.Murray@warwick.ac.uk
}

Please cite as: Stanley, P. and Murray, N. (2013). 'Qualified?' A framework for comparing ELT teacher preparation courses. Australian Review of Applied Linguistics 36/1: 102-115

Keywords: Language teaching capital; 'qualified language teacher'; ELT qualification standards; language teacher expertise; interculturality; CELTA; Masters degrees in TESOL.

\begin{abstract}
There is no standard via which to measure the 'qualified' English language teacher in a way that is meaningful to institutions seeking to employ teaching staff. This is significant given that candidates may differ markedly in their language competence, knowledge about language, methodological skills and ability to explain and justify their praxis and operate in intercultural spaces. In this article, we propose a framework, based on Bourdieu's (1986) 'forms of capital', with a view to helping stakeholders articulate and evaluate teachers' skills. To demonstrate how this framework might be used, we apply it to two English language teacher qualifications that have wide professional currency: CELTA courses and Masters degrees in ELT/Applied Linguistics.
\end{abstract}

\section{Introduction}

The notion of a 'qualified' English language teacher is somewhat nebulous; it means different things to different people in different contexts. This is evident from the fact that institutions vary widely in their qualifications requirements for English language teachers. In some contexts, for example, being a native speaker (sometimes with a first degree and/or an entry-level ELT [English Language Teaching] qualification) is the only qualification required, while in others, particularly higher education, a Masters degree or, increasingly, a PhD, in Applied Linguistics or ELT may be sought. Although it is clear that untrained 'teachers' cannot legitimately be regarded as 'qualified', higher degrees assessed by coursework and/or research used as teaching qualifications raise issues of their own. In addition, pre-service ELT qualifications and course providers abound and it can be difficult for employers to navigate the skills and knowledge types that teachers may acquire on different pathways into the profession. 
In this article, we propose an ELT 'teaching capital' framework with the intention of providing employers with a means of navigating the various skills and knowledge types that a 'qualified' English language teacher may need, depending on the teaching context, and, therefore, what type and level of ELT qualification it is appropriate to demand of potential teachers. In addition, the framework furnishes employers, as well training providers and teachers themselves, with a conceptual tool via which to consider in a more meaningful way the particular skills and knowledge bases different ELT qualifications confer. This in turn allows for an improved understanding of the areas in which additional support and professional development may be required.

At the outset, it is important to qualify what we mean by the term 'qualified', for at least two interpretations are possible: credentialled and prepared/equipped. In some English language teaching contexts, for instance, accredited schools can only employ teachers who are 'appropriately qualified', that is, credentialled according appropriate certification. But this is not the sense in which we discuss teachers' qualifications. Indeed, the purpose of this paper is to problematize the notion that a 'credentialled' teacher is necessarily fully qualified to do the job. Instead, we conceptualize 'qualified' to mean a teacher who is appropriately knowledgeable and able to undertake the job at hand. A separate question, not considered here, is the question of teachers' identities: attitudes and dispositions, degree and types of motivation, enthusiasm, people skills, and so on. These also form part of a teacher's armoury but we do not regard these factors as qualifications, as such. Instead, our discussion focuses on the learnable: what teachers need to know and what they need to be able to do in order to be 'qualified' to do the job.

\section{What makes a qualified English language teacher?}

Regardless of the variation in the way it is interpreted and used by individuals and institutions operating in multiple different contexts, the notion of 'the qualified teacher' presupposes, nonetheless, that there exists a core set of skills and abilities shared by those to whom this label is attributed. In attempting to define what these are, we feel there is value in invoking and adapting Bourdieu's (1986) model of capital. This model theorizes the exchange value not only of economic capital but also social, cultural, and symbolic forms of capital. Within this framework, cultural capital refers to knowledge, skills, education, attitudes, dispositions, and other attributes that increase the likelihood of success in the prevailing educational, employment and socio-cultural system. Social capital is defined by Bourdieu as 'the aggregate of the actual or potential resources which are linked to possession of a durable network of more or less institutionalized relationships of mutual acquaintance and recognition' (Bourdieu 1986, 51); that is the resources of relationships, connections, group memberships, and networks of influence and support, both in and of themselves and for their instrumental value in achieving other ends. Such ends may include the usefulness of social connections in providing direct and indirect access to other forms of capital, such as economic capital through employment; thus economic capital can be acquired through leveraging social capital, for example. Symbolic capital refers to the intrinsic value of social status, 
honour or recognition. All forms of capital may have both their own intrinsic value as well as symbolic value; and symbolic value may, in turn, result in the acquisition of other forms of capital.

Bourdieu's model is elegant and highly durable in that, while there is some conceptual overlap between forms of capital, the entire terrain is covered. Thus capital can be conceptualized, and its relative worth compared, in an infinite variety of domains using the same framework. So while, for example, the cultural, social and symbolic capital, respectively, of theoretical understandings, academic and job titles, institutions and well-connected friends may be accorded great value at an academic conference, the very same capital is of much more limited worth in, for example, a gym. Meanwhile, in a gym setting there may be quite different markers of cultural, social, and symbolic capital - informed discussions of training regimes, connections with professional athletes, and the embodied symbolic capital of a toned, tanned body, for instance. These forms of capital are likely to be accorded very limited value in an academic setting. But the same framework can be meaningfully applied in both domains. We aim to emulate this function of universal applicability in our proposed framework.

Drawing on Bourdieu, our framework of teaching capital divides English language teaching skills and knowledge into three domains: language capital, methodological capital and intercultural capital. Each of these is sub-divided into the declarative (knowing that) and the procedural (knowing how). So, for example, while competent users of English can use the language, many will lack the capacity to analyze and articulate its grammatical and other systems. Conversely, a learner of English may have a comprehensive knowledge about the language without necessarily being able to deploy that knowledge appropriately in contexts of language use. These are two examples from the domain of language capital that isolate, respectively, the procedural and declarative knowledge types.

A similar duality exists within each of methodological and intercultural capital. An instinctive teacher may exhibit the ability to teach without consciously knowing the methodological rationale informing what s/he does. In contrast, an individual conversant in language teaching methodology may not necessarily have the skills to apply that knowledge in a manner that maximizes student engagement and uptake. Similarly, an individual may have an intellectual appreciation of cultural difference but lack the practical ability to negotiate between cultures. This contrasts with the intercultural capital exhibited by someone who has a natural ability to traverse cultures but who is unable to deconstruct that process. 


\begin{tabular}{|c|c|c|c|}
\hline language & methodology & interculturality & \\
\hline $\begin{array}{l}\text { Knowledge about } \\
\text { language }\end{array}$ & $\begin{array}{l}\text { Knowledge about } \\
\text { teaching }\end{array}$ & $\begin{array}{l}\text { Knowledge \& } \\
\text { appreciation of } \\
\text { cultural } \\
\text { differences; } \\
\text { knowledge about } \\
\text { specific culture(s) }\end{array}$ & Declarative \\
\hline $\begin{array}{l}\text { Ability to use a } \\
\text { variety of English } \\
\text { appropriate to the } \\
\text { needs of the } \\
\text { learners }\end{array}$ & $\begin{array}{l}\text { Ability to teach in } \\
\text { contextually } \\
\text { appropriate } \\
\text { way(s) }\end{array}$ & $\begin{array}{l}\text { Ability to interact } \\
\text { across cultures }\end{array}$ & Procedural \\
\hline
\end{tabular}

Figure 1: A model of teaching capital

As with Bourdieu's model, there is some overlap between these conceptual areas. For example, while the articulation of grammatical understanding may be conceptualized as a declarative knowledge of language, the act of delivering such an explanation in a way that engages learners can be considered a form of procedural methodological capital. And, indeed, the decision as to whether to explain the grammar deductively at all or perhaps, instead, lead students to its discovery inductively will depend on procedural intercultural capital as well as on the procedural methodological capital of formulating an appropriate lesson plan and devising and using teaching materials. So, the separation of these forms of teaching capital is somewhat artificial. However, isolating each capital type allows for an analysis of where, exactly, a teacher may be said to be 'qualified' or lacking. And, crucially, as with Bourdieu's model, the whole terrain of teaching capital is covered. This is why we have chosen the three areas described above, as, between them, they cover most, if not all of what we believe an English language teacher needs to know and to be able to do.

Our model of teaching capital serves as a framework via which to measure the extent to which a teacher can be regarded as 'qualified'. We believe that a 'qualified' English language teacher needs to have, or be supported in their development of, all three of the above types of capital both as procedural and declarative knowledge (see figure 1). The framework we propose synthesizes and builds on other taxonomies of English language teacher competencies, in particular those of Pasternak and Bailey (2004) and Tsui (2003).

Pasternak and Bailey's (2004) model, which frames an analysis of native and nonnative teacher strengths, similarly differentiated declarative and procedural knowledge types in the three cognate areas of language, teaching, and culture. However, this framework conceptualizes 'culture' as 'knowledge about' (declarative) and 'ability to do' (procedural) in the 'target culture'. But, whose culture exactly? If, for example, British English' is the target language, which culture 
is the target culture? Is it the cultures of Cambridge dons, Yorkshire factory workers, or Black London Youth? If English is a lingua franca, there can be no single 'target culture' and as such the goal of learning should be the acquisition of generic intercultural skills that equip learners to interact effectively and appropriately with interlocutors from myriad 'other' cultures. Furthermore, there is an issue of teachers' proficiency in students' cultures, including their cultures of learning (Jin \& Cortazzi 2006). In Pasternak and Bailey's model, 'procedural knowledge' in the domain of teaching is not problematized. If teaching is context dependent, as we assert, there can be no single 'teaching capital', procedural or otherwise. Instead, the ability to teach, along with knowledge about teaching, are dependent on the context of teaching. While 'non-native' teachers may be assumed to be able to teach in culturally appropriate ways if they teach students from their own countries, plenty of teachers, both native and non-native, teach outside of their 'own' cultures. Further, if culture is conceptualized as multiple, hybrid, and negotiated rather than as national and homogenous, even teachers who share the same nationality as their students do not necessarily share their cultures, particularly where there are generational or regional differences in, for example, learning styles, curriculum ideologies, epistemologies, and expectations of teacher roles.

Tsui's (2003) model is similarly partial, although in considering 'situated knowledge' (50-52) it does address the question of context specificity of procedural teaching capital. Its emphasis, however, is on the stages of development of teacher expertise rather than the nature of teaching capital across different contexts of teaching. While Tsui differentiates between 'knowing how' and 'content knowledge' and includes reflective practice (conceptualized here as part of declarative teaching capital) and the integration of different types of teaching capital, interculturality is sidelined both as a goal of language teaching and as a component of procedural teaching capital.

Extant models of language teacher expertise, then, while strong bases for the present framework, are insufficiently finely tuned to allow for a meaningful comparison among all teacher types. The present model addresses this issue.

Having described the model, we now provide an example of how it might be used by employers and other stakeholders to determine potential 'training gaps' in teachers' abilities. Our focus is two common ELT qualification types: Masters courses in Applied Linguistics/ELT and the Cambridge CELTA (Certificate in English Language Teaching to Adults), a popular 'short' ELT certificate course. The reason we have chosen these qualifications as examples is that they are common among English language teachers and maintain high currency with ELT employers. We also wish to propose that, when viewed through the 'teaching capital' framework prism, there are perhaps grounds for arguing that CELTA-type courses tend to be undervalued, while Masters courses are sometimes overvalued. 


\section{Language Capital}

In terms of declarative language capital (knowledge about language), Masters programmes generally give a good account of themselves, with the majority including at least one course that focuses on the formal language system or a series of discrete stand-alone courses which typically cover grammar, discourse, phonology, semantics and lexis (Murray and Crichton 2010). Knowledge of these areas of language is one component of teaching capital. We would argue that pragmatics, a field that also frequently features in Masters programmes, represents a point of intersection between language capital and intercultural capital - both declarative. Students' grasp of declarative language capital is generally assessed explicitly, via assignments on particular linguistic features or phenomena.

Procedural language capital is, broadly speaking, the ability to use English. Specifically, we define it as the extent to which applied linguistics/TESOL students exhibit a degree of communicative competence that ensures they are able to cope with the demands of a postgraduate subject that has language at its heart, and ultimately, to teach English effectively in whichever context they find themselves operating. Such demands should, in theory, be reflected in the language entry requirements stipulated by the institution. However, what is regarded as 'adequate' English varies considerably. While some universities' stipulate an IELTS 6.0 - a level IELTS itself suggests indicates a need for '[further] English study ... for linguistically demanding academic courses', others require a minimum of IELTS 7.0 or equivalent. Furthermore, although a minority of Masters degrees incorporate an English language development component, personal experience suggests that graduates of such programmes may lack a level of communicative competence commensurate with being an effective teacher of English. We stress that this is not an issue of nativeness versus non-nativeness but of ethical responsibility: accepting candidates with inadequate language proficiency onto applied linguistics/TESOL programmes risks setting them up to struggle - and possibly fail - either as students or, subsequently, in the workplace.

Like Masters courses, the CELTA and other similar courses have languageknowledge criteria in their assessment frameworks, although this is assessed more through the practical teaching component than it is through written assignments. Declarative language knowledge is thus integrated with procedural methodological capital on the CELTA. This could mean, for example, trainee teachers researching modal verbs of deduction (thereby acquiring [often quite superficial] declarative knowledge) and subsequently providing practice for a group of students with varying levels of proficiency (application - or procedural methodological capital). In this way, knowledge is combined with teaching skills and thus has the advantage of providing an opportunity for course participants to reflect on practice and ways of improving their pedagogy. However, this comes at a price. What these courses tend to omit is a more wide-ranging, in-depth and holistic declarative knowledge of the language system; indeed, teachers trained on certificate-level courses often report weakness in their language awareness, particularly grammar (Kanowski 2004; Green 2005). 
Procedural language capital is assumed but not taught on the CELTA, and the required language level of prospective candidates is rigorously checked upon entry (generally IELTS 7.5) and in the assessment both of written texts and teaching practice (Cambridge ESOL 2003). This ensures that students with inadequate spoken and written English skills will generally fail to gain admission to the course. It also means that, while it is beyond the scope of the CELTA to develop trainees' proficiency in English, the higher entry requirement means employers can be fairly confident of CELTA graduates' procedural language skills, if not necessarily of their declarative language knowledge.

\section{Methodological capital}

The majority of Masters programmes include a core methodology component within such courses as Language Teaching Methodology, A History of Methods \& Approaches, Principle \& Practice in Language Teaching, Communicative Approaches to Language Teaching, and Lesson Planning \& Materials Development (Murray and Crichton 2010). It is these and similar courses that constitute a focus on developing declarative methodological capital in students by giving them an overview of the various methods and approaches that have appeared in the field over the years and the theories of language and learning on which they are based. Other core courses that can be considered part of methodological capital include language testing, where declarative knowledge would include an understanding of elements such as test design, validity, reliability etc.

Importantly, this declarative methodological capital provides students with the wherewithal to return to 'first principles' and adjust and adapt their pedagogy according to local teaching contexts. That is, because they understand methodological foundations and are not simply applying, wholesale and without reflection, a particular prescribed approach, they are well positioned to make informed judgements about which approach, elements of an approach or mix of approaches is most appropriate to any given context, and are able to shape pedagogy accordingly. Ramsden's (1992) model, in figure 2, serves to help illustrate this relationship between declarative methodological capital and its procedural counterpart. 


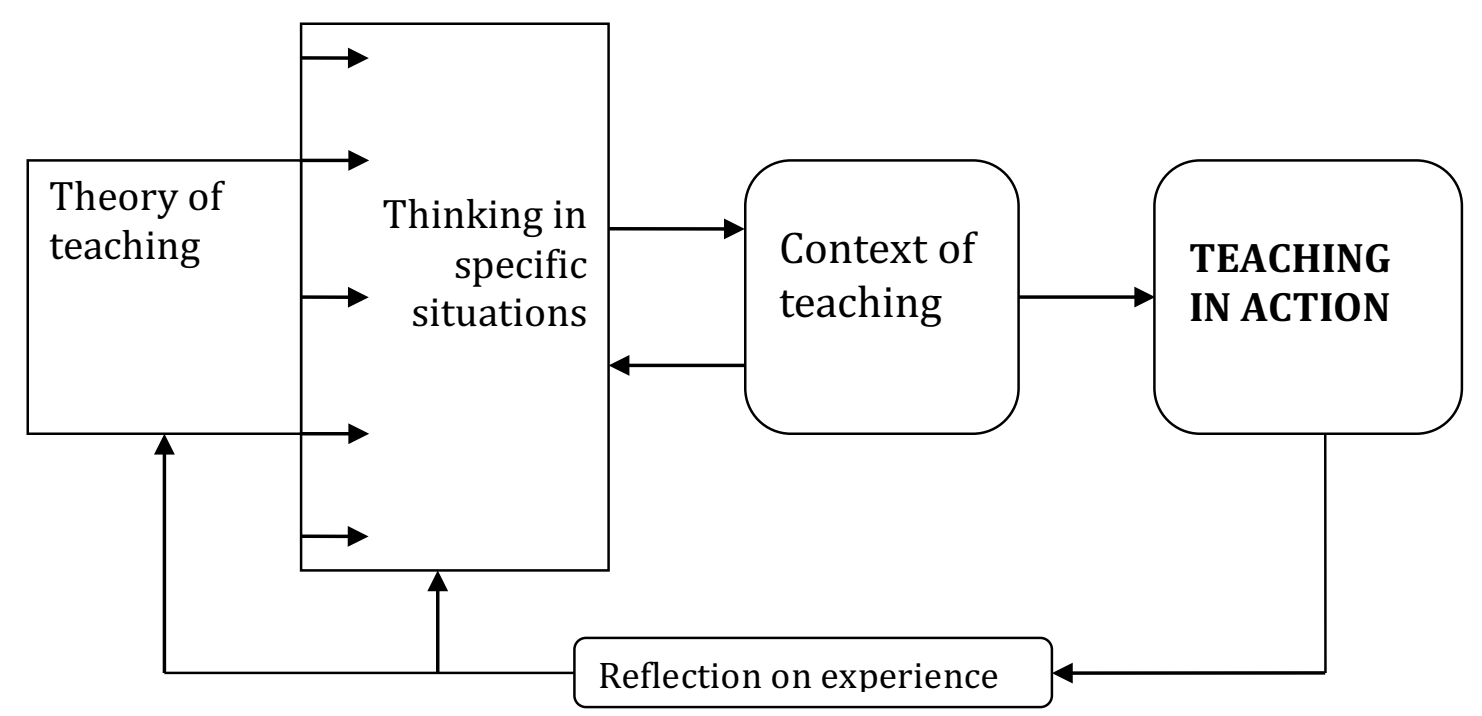

Figure 2: Ramsden's (1992, p.119) model of teaching in higher education

It is the capacity to actually implement a particular approach or method, including associated skills such as planning and conducting constructive alignment and assessment, that comprises procedural methodological capital. Within Masters programmes, demonstrations are commonly given of particular teaching methods, along with the opportunity for practice with fellow students. However, Masters degrees in ELT/Applied Linguistics are variable in terms of whether and to what extent they include an assessed teaching practice component with real Englishlanguage students (as opposed to peer or micro-teaching). Instead, procedural methodological capital tends to be developed by having students construct and justify lesson plans for a defined student group. Significantly, however, meaningful engagement with concepts, ideas and tasks is often possible for the reason that many Masters programmes require students to have two or more years teaching experience.

The CELTA differs from Masters degrees in that procedural methodological capital is prioritized over declarative knowledge with the result that students may be able to perform 'appropriate' classroom behaviours but have little awareness of why they are doing what they do. Such courses have thus been criticized as overly prescriptive and offering a superficial quick-fix 'toolkit' of classroom skills. While some awareness of underlying theory and lesson/activity aims is taught, reflection focuses more on how the use of techniques might be improved in practice than on the rationale behind the methodology itself (Ferguson and Donno 2003; Horne 2003; Macpherson 2003; Kanowski 2004). Stanley's (2013) TESOL Certificate toolkit model of teaching (Figure 3) illustrates this approach. 


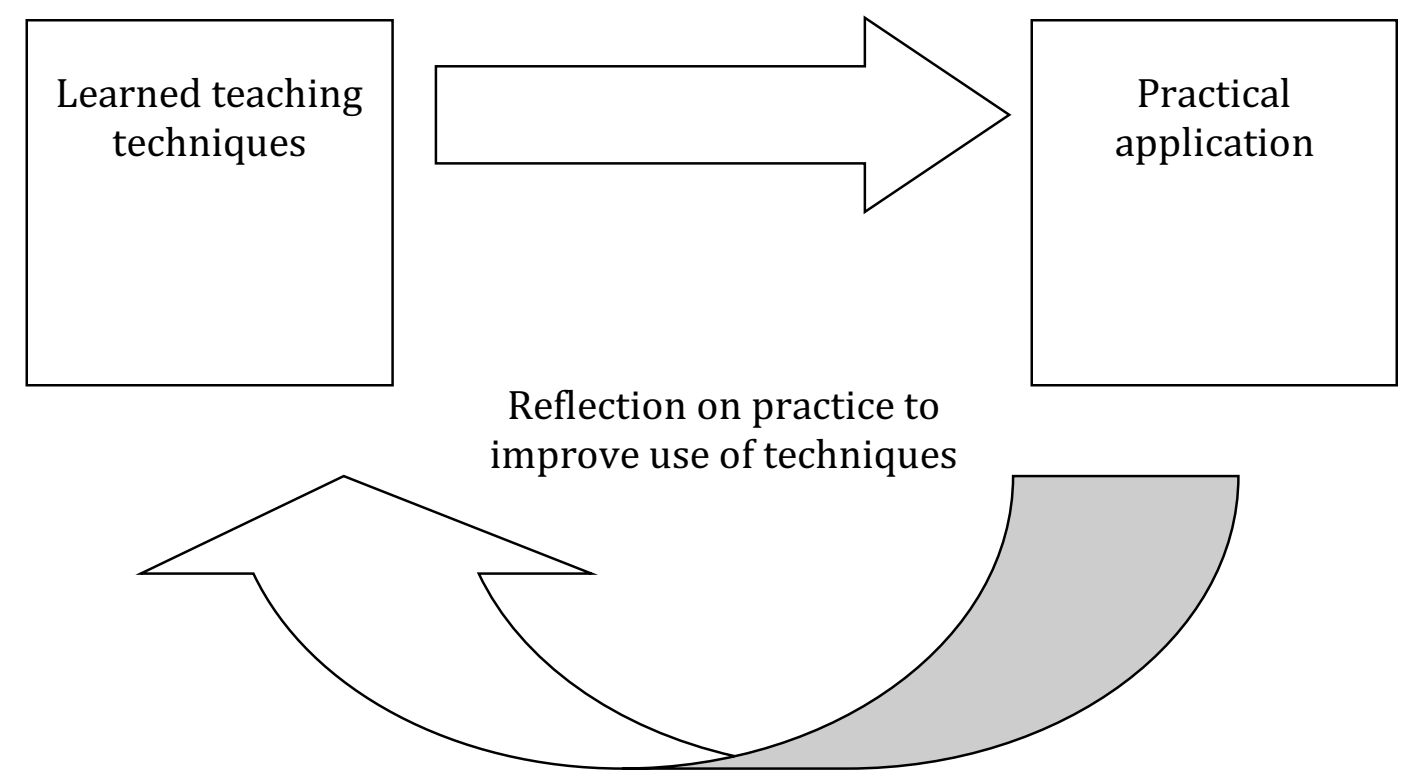

Figure 3: Conceptual model of teaching as a 'toolkit', as exemplified in CELTA-type certificate TESOL courses (Stanley, 2013, p.7)

However, the CELTA's focus on procedural rather than declarative methodological capital can be seen as a strength: comparing training types, Kanowski $(2004,22)$ found that some teachers valued CELTA over Masters courses that were seen as 'too theoretical'. Among the practically-focused CELTA assessment criteria, for example, are the following:

- Setting up whole class and/or group or individual activities appropriate to the lesson type

- Managing the learning process in such a way that lesson aims are achieved

- Making use of materials, resources and technical aids in such a way that they enhance learning

- Using appropriate means to make instructions for tasks and activities clear to learners

- Using a range of questions effectively for the purpose of elicitation and checking of understanding

- $\quad$ Providing learners with appropriate feedback on tasks and activities

- Maintaining an appropriate learning pace in relation to materials, tasks and activities

- Monitoring learners appropriately in relation to the task or activity

- Allocating appropriate timing for different stages in the lessons

(Cambridge ESOL 2003)

This means that although teachers may emerge from the CELTA with little declarative methodological capital, employers can be confident that they are able manage a classroom and perform the role of a teacher, regardless of whether or not they can explain what they are doing. While it is clear that teachers require both types of capital, given a choice of declarative or procedural knowledge, employers 
may place greater value on the type of capital that allows teachers to get into the classroom and begin teaching. This transition from training to practice may be relatively seamless where the contexts of training and practice are similar, but CELTA-trained teachers report difficulties where contexts differ substantially, such as when they are required to teach younger learners (Green 2005) or where students' cultures of learning may make them question the communicative methods taught (almost exclusively) on CELTA-type courses (Bax 2003). In such cases, we would suggest that Masters-qualified teachers would be better equipped to go back to 'first principles' in constructing contextually appropriate pedagogies.

\section{Intercultural capital}

Declarative intercultural capital is developed in Masters programmes most explicitly through courses such as pragmatics (where language and the expression and interpretation of meaning are considered within the context of cultural norms), sociolinguistics, discourse analysis and/or intercultural communication. Additionally, awareness can be developed implicitly through analysis of constructs such as communicative competence and associated notions of context, appropriateness and sociolinguistic competence. Procedural intercultural capital is accrued most obviously in the very process of students interacting with their peers in Masters programmes that are increasingly multicultural in terms of the makeup of the student body. In addition, for many teachers, an ELT Masters degree is an opportunity to spend an extended period living outside their home country and during which they inevitably negotiate interculturality on a daily basis.

Interculturality is neglected in the assessment criteria of the CELTA, which prioritize practical teaching methodology and a limited declarative knowledge of language. There is little time for widening their scope to include the development of students' intercultural capital, whether declarative or procedural. However, there is scope for the creative interpretation of course criteria to justify the inclusion of cultural content and an awareness of cultures of learning. For example, the CELTA's assessment criteria include the following:

- Teaching a class with an awareness of learning styles and cultural factors that may affect learning

- Acknowledging, when necessary, learners' backgrounds and previous learning experiences

- Establishing good rapport with learners and ensuring they are fully involved in learning activities

- $\quad$ Providing clear contexts and a communicative focus for language

- Showing awareness of differences in register

The inclusion of explicit cultural content under these criteria relies on trainers' own interpretation of the assessment criteria, and their familiarity with and belief in the importance of intercultural capital as a component of teacher capital. This may in turn depend on the trainer's own educational and experiential backgrounds, as there is little backwash pressure from assessment to make it integral. As a result, 
students' development of declarative intercultural capital is not guaranteed on such courses. As in Masters programmes, the development of students' procedural intercultural capital is process based rather than taught explicitly. CELTA courses are available around the world and students often travel to undertake courses in countries other than their own. Whether in an English-dominant context (e.g. Sydney or London) or a non English-dominant one (e.g. Barcelona or Cairo), candidates are exposed to intercultural communication by virtue of the fact that their teaching practice students and/or peers and trainers are likely to be from multiple countries. It is the case, therefore, that undertaking a CELTA is likely to involve experiencing real-life intercultural communication and negotiation.

\section{Discussion and conclusion}

Given the absence of an industry standard as to what constitutes a 'qualified' English language teacher, and the resultant variability in what different organizations require of those looking to secure English language teaching positions, we believe that there is value in the kind of teaching capital framework proposed here and which allows for a meaningful analysis and comparison of programme and teacher 'types'. In road testing that framework, we have acquired an interesting and insightful perspective on the two qualification types invoked for that purpose: the Cambridge Certificate in English Language Teaching to Adults (CELTA), and the Masters degree in ELT/Applied Linguistics. We conclude with a summary of our reflections.

The CELTA retains high currency particularly in language schools. However, it is frequently criticized on the grounds that it tries to achieve more than is possible is a one-month training programme. At issue is its solution-based training model: course brevity can be achieved only by reducing teaching to a series of formulaic moves that are replicated though practice. Teaching, however, is a far more complex undertaking that cannot be reduced to surface-level learning and the replication of such moves - a going through the 'correct' motions. If teaching were entirely predictable, and if the teaching context were very similar to the training context, this model might be sufficient, and certificate-trained teachers could hope to enjoy classroom success. But it is not. Teachers frequently encounter different cultures of education, different student types and new classroom situations, and this means that a one-size-fits-all toolkit that 'works' in the training environment may not work elsewhere. Without a clear understanding of the underpinning methodological rationale, teachers may flounder. Applying the teaching capital framework to the type of skills and knowledge assumed and conferred by such courses helps make this shortcoming apparent.

There is good reason, then, to doubt the roundedness of trainees who graduate from CELTA-type programmes. Not only are they equipped with fairly minimal systemic knowledge of English and a modest 6-8 hours of observed classroom teaching practice but, more importantly, they lack the facility - associated with education rather than training programmes - to reflect on their practice in light of theory and to adjust their pedagogical approaches according to teaching circumstances. 
Encouraging such informed reflection and flexibility is a luxury not permitted in a programme whose main objective (rightly or wrongly) is to get teachers into English language classrooms as quickly as possible with a few key 'survival' techniques in their armoury. We believe that language students, who often pay substantial tuition fees, have a right to teachers who have undergone more robust preparation and who have the ability to reflect on and, where necessary, adapt their declarative and procedural knowledge respectively. Moreover, the profession has an ethical responsibility to ensure that it produces such teachers and that it does not consent to anything less.

On their own terms, however, CELTA-type courses do all that can reasonably be asked of a programme of one-month's duration and it is perhaps the language schools - and other organizations - that regard it, alone, as adequate teacher preparation, whose judgement needs questioning.

For those institutions that see a Masters in TESOL as the gold standard, there is a need to be equally discriminating and take the trouble to investigate the particular degree programme from which candidates for teaching positions have graduated and the rigor with which standards have been upheld in selecting and assessing candidates. While many ELT Masters programmes share core components, this is not true of a teaching practicum. We would contend that teachers whose Masters degrees either lacked a practical teaching component altogether, or incorporated a practicum that was not assessed by suitably qualified and standardized teacher educators, are not ideally qualified to teach. Where students are teaching and studying simultaneously, this is something of a halfway house - not ideal in that it is not observed, but with the advantage of giving students the opportunity to apply immediately what they are learning in their ELT programme. In addition, the requirement to undertake an assessed teaching practicum allows for the identification of candidates whose own procedural knowledge of English is insufficient for them to be effective as teachers of the language. However, our experience in the ELT industry indicates that regardless of this fact, a significant number of such candidates go on to graduate and become practising teachers. In the same way as we would question the ethics of CELTA-only teachers, we equally question the practice of hiring teachers whose own procedural knowledge of English is insufficient or, in the case of graduates of Masters degrees lacking a properly assessed practicum, unproven.

We would argue, therefore, that neither CELTA-type qualifications nor Masters degrees in TESOL are, in themselves, adequate preparation in all six areas of our 'qualified teacher' framework. While CELTA-trained teachers may enjoy procedural knowledge of language and pedagogy, most will lack declarative knowledge of these areas and also of interculturality. Similarly, while we would expect Masterseducated teachers to have a thorough grounding in pedagogical, linguistic and perhaps intercultural declarative knowledge, their ability to apply this may be less convincing as many will lack procedural knowledge of pedagogy and perhaps also language. Teachers qualified by either CELTA or Masters degrees may or may not 
enjoy intercultural procedural knowledge depending on their individual circumstances; neither qualification offers any guarantees in this respect.

The framework we have outlined is designed to help institutions and other stakeholders, including training bodies and teachers themselves, to both understand the strengths as well as identify and rectify the skills and knowledge 'gaps' that can result from different types of teacher preparation. This is vital, and our road test suggests that neither CELTA-type courses nor Masters degrees in ELT/Applied Linguistics - the two types on which we have chosen to focus - confer a complete set of ELT skills. Furthermore, certain ESL/EFL contexts may require a more nuanced evaluation of how qualified a given teacher is. For example, where the teaching of younger children or adolescents is the primary concern, employers may look for evidence of a degree module such as 'Teaching Young Learners' within applicants' Master's degree transcripts - possibly in addition to a more general education qualification. In this respect, the framework outlined here would serve as an initial screening mechanism. Notwithstanding this, other course types may tick more of the boxes on the teaching capital framework than either a Masters degree or CELTA: Cambridge DELTA (Diploma in English Language Teaching to Adults) may be one such course, as might a Bachelors degree in Education with a substantial, suitably assessed, teaching practicum focusing on ELT. As with Masters and CELTA programmes, the proposed framework offers a critical tool with which to evaluate those alternatives.

\section{References}

Bax, S. 2003. 'The end of CLT: A context approach to language teaching'. ELT Journal 57(3): 278-287.

Bourdieu, P. 1986. 'The forms of capital'. In Handbook for Theory and Research for the Sociology of Education, edited by Richardson, J. G. New York: Greenwood Press, 214-258.

Cambridge ESOL 2003. 'CELTA syllabus and assessment guidelines'. Cambridge, University of Cambridge ESOL Teaching Awards.

Ferguson, G; Donno, S. 2003. One-month teacher training courses: Time for a change? ELT Journal 57(1): 26-33.

Green, T. 2005. 'Staying in touch: Tracking the career paths of CELTA graduates'. University of Cambridge ESOL Research Notes 19, 7-11.

Horne, S. 2003. 'Readers Respond: Short teacher training courses'. ELT Journal 57(4): 395-397.

IELTS 2009. IELTS Guide for Educational Institutions, Governments, Professional Bodies, and Commercial Organisations. Accessed 7 April 2012. Available from: 
http://www.ielts.org/PDF/IELTS\%20Guide\%20for\%20Stakeholders\%20March\%2 0200 9.pdf).

Kanowski, S. 2004. 'Helter CELTA: Do short courses equal 'best practice' in teacher training?' TESOL in Context 13(2): 21-27.

Macpherson, S. 2003. 'Readers respond: The short intensive teacher-training course'. ELT Journal 57(3): 297-300.

Murray, N; Crichton, J. 2010. 'What's in a name? Degree programs and what they tell us about applied linguistics in Australia'. Australian Review of Applied Linguistics 33(2): 15.1-15.16.

Pasternak, M; Bailey, K. M. 2004. 'Preparing nonnative and native English-speaking teachers: Issues of professionalism and proficiency'. In Learning and Teaching from Experience: Perspectives on Nonnative English-Speaking Professionals, edited by Kamhi-Stein, L. D. Ann Arbor, University of Michigan, 155-175.

Ramsden, P. 1992. Learning to teach in higher education. London: Routledge.

Stanley, P. (2013). A Critical Ethnography of 'Westerners' Teaching English in China: Shanghaied in Shanghai. London: Routledge.

Tsui, A. B. M. 2003. Understanding Expertise in Teaching: Case Studies of Second Language Teachers. Cambridge: Cambridge University Press. 